powder inhaler to budesonide Turbuhaler. Eur Respir $J$ 2000; 16: 808-816.

2. Boulet LP, Cockcroft DW, Toogood J, Lacasse Y, Baskerville J, Hargreave FE. Comparative assessment of safety and efficacy of inhaled corticosteroids: Report of a Committee of the Canadian Thoracic Society. Eur Respir J 1998; 11: 1194-1210.

3. Busse WW, Chervinsky P, Condemi J, et al. Budesonide delivered by Turbuhaler is effective in a dosedependent fashion when used in the treatment of adult patients with chronic asthma. J Allergy Clin Immunol 1998; 101: 457-463.

4. Pauwels RA, Löfdahl CG, Postma DS, et al. Effect ofinhaled formoterol and budesonide on exacerbations of asthma. N Engl J Med 1997; 337: 1405-1411.

5. Agertoft L, Pedersen S. A randomized, double-blind dose reduction study to compare the minimal effective dose of budesonide Turbuhaler and fluticasone propionate Diskhaler. J Allergy Clin Immunol 1997; 99: $773-780$.
6. $\mathrm{O}^{\prime}$ Connor BJ, Bonnaud G, Luna JM, SanchezBorges M, Lutsky BN. Comparison of mometasone furoate (MF) administered by dry powder inhaler (DPI) with fluticasone propionate (FP) administered by Diskhaler in patients with moderate persistent asthma. Eur Respir J 1999; 14: Suppl. 30, 197s.

7. Affrime MB, Cuss F, Padhi D, et al. Bioavailability and metabolism of mometasone furoate following administration by metered-dose and dry-powder inhalers in healthy human volunteers. J Clin Pharmacol 2000; 40: $1227-1236$.

8. Affrime MB, Kosoglou T, Thonoor CM, Flannery BE, Herron JM. Mometasone furoate has minimal effects on the hypothalamic-pituitary-adrenal axis when delivered at high doses. Chest 2000; 118: $1538-1546$.

9. Lipworth BJ, Jackson CM. Safety of inhaled and intranasal corticosteroids-Lessons for the new millenium. Drug Safety 2000; 23: 11-33.

\title{
Lung cancer in young females
}

\section{To the Editor:}

We read with interest the article by LIENERT et al. [1]. Based on data of the clinical cancer registry at the Lungenklinik Heckeshorn, Berlin, 1986-1995, the authors examined whether young female lung cancer patients ( $\leq 45$ yrs of age, $n=96)$ differ from all other lung cancer patients $(n=4,843)$ with respect to risk factors, histology and clinical features. They found a higher proportion of adenocarcinomas (38\%) and carcinoids in young females. Other main characteristics of young females were a high proportion of eversmokers $(88 \%)$ and a large number of patients who reported a first degree relative with lung cancer (13\%). We would like to add our recent findings of a largescaled, case-control study of lung cancer conducted in Germany from 1990-1996 [2, 3], which aimed to investigate risk factors for lung cancer in young adults. This study included 251 young patients and 280 population controls ( $\leq 45$ yrs of age), as well as 2,009 older cases and 2,039 older controls $(55-69$ yrs of age). Adenocarcinomas were more frequent in young males $(41 \%)$ and young and older females $(44 \%$ and $47 \%$, respectively) than in older males $(28 \%)$. Differences in histology between age groups could be explained, in part, by differences in smoking patterns. However, there are still unknown factors that appear to favour the development of adenocarcinoma in the young [3]. A history of lung cancer in first degree relatives was associated with a 2.6 -fold (95\% confidence interval (CI) 1.1-6.0) increased risk in the young, while no elevated risk was observed in the older group (odds ratio $=1.2$ 95\% CI 0.9-1.6). Additional evidence for an age-specific genetic predisposition in lung cancer was recently provided by GAUDERMAN and MORRISON [4]. About $80 \%$ of our young female cases were current smokers, demonstrating a 30-fold increased lung cancer risk compared to never-smoking young females [2]. As stated by
LIENERT et al. [1], smoking is the main risk factor for lung cancer in young females. This was recently supported in a pooled analysis of European casecontrol studies of lung cancer in young females [5], where $84 \%$ of female patients aged $40-45$ yrs could be attributed to active smoking.

\section{Kreuzer*, H.E. Wichmann ${ }^{\#}$}

*Federal Office of Radiation Protection, Institute of Radiation Hygiene and ${ }^{\#}$ GSF-Institute of Epidemiology, Ingolstädter Landstr. 1, 85764 Neuherberg, Germany.

\section{References}

1. Lienert T, Serke M, Schönfeld N, Loddenkemper R. Lung cancer in young females. Eur Respir J 2000; 16: 986-990.

2. Kreuzer M, Kreienbrock L, Gerken M, et al. Risk factors for lung cancer in young adults. Am J Epidemiol 1998; 147: 1028 - 1037.

3. Kreuzer M, Kreienbrock L, Müller KM, Gerken M, Wichmann HE. Histologic types of lung carcinoma and age at onset. Cancer 1999; 85: $1958-1965$.

4. Gauderman WJ, Morrison JL. Evidence for agespecific genetic relative risks in lung cancer. $\mathrm{Am}$ J Epidemiol 2000; 151: 41 - 49.

5. Boffetta P, Kreuzer M, Benhamou S, et al. Risk of lung cancer from tobacco smoking among young women from Europe. Int J Cancer 2001; 91: 745-746.

\section{From the authors:}

The valuable data of our colleagues M. Kreuzer and H.E. Wichmann support the main results from our own series. Yet it is remarkable that in their patients, adenocarcinoma in older females $(55-69$ yrs of age) 